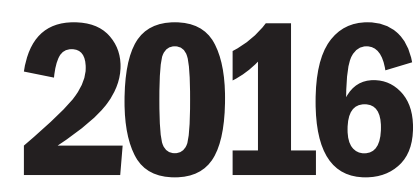

volume 13 | issue 1 an open access journal for architectural research

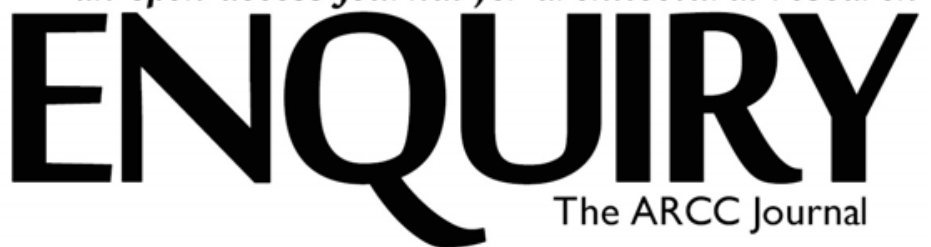

\title{
Architectural Documentation Through Thick Description
}

\author{
Serra Akboy-ilk, PhD
}

\begin{abstract}
Architectural documentation focuses on deconstructing the built environment in the form of two-dimensional measured drawings. Documentation activities, therefore, seem to be purely technical exercises that afford documenters the ability to collect metric data from architectural surfaces and then to transform field data into graphical representations. However, architectural documentation involves more than just the technical reproduction of a context as it involves an intellectual effort to thickly describe the socio-cultural heritage setting. During the process, documenters conduct an informed survey and bring all the knowledge with them in order to decode the cultural signifiers embedded in the architectural heritage. Discussing measured drawings as an interpretive account of the built environment and surveying practices as a means to acquire heritage information, this article examines architectural documentation through the lens of thick description.
\end{abstract}

Keywords: Architectural documentation; drawing; thick description; interpretation.

\section{Permissions and copyright}

Authors retain copyright and grant the journal right of first publication with the work simultaneously licensed under a Creative Commons Attribution License that allows others to share the work with an acknowledgement of the work's authorship and initial publication in this journal.

Attribution-NonCommercial-ShareAlike 4.0 International (CC BY-NC-SA 4.0)

You are free to: Share - copy and redistribute the material in any medium or format. Adapt - remix, transform, and build upon the material for any purpose. You may not use the material for commercial purposes. The licensor cannot revoke these freedoms as long as you follow the license terms.

Under the following terms: Attribution - You must give appropriate credit, provide a link to the license and indicate if changes were made. You may do so in any reasonable manner, but not in any way that suggests the licensor endorses you or your use.

No additional restrictions - You may not apply legal terms or technological measures that legally restrict others from doing anything the license permits.

How to cite:

Akboy-llk, Serra. 2016. "Architectural Documentation Through Thick Description." Enquiry 13 (1):

17-29. Http://dx.doi.org/10.17831/enq:arcc.v13i2.400

\section{INTRODUCTION}

"The nature of inquiry in the discipline of architecture is not different from research in other fields. The researcher observes the phenomenon of object, makes hypotheses, gathers data, undertakes rigorous analysis, and uses the data to draw conclusions that form the basis for action" (Woodcock 2006: 37).

Documentation through drawing is a human endeavor that is interrelated with practices of observation, thinking, elaboration, and interpretation. In the classical tradition, a Corinthian maid's efforts to trace the shadow of her departing lover on a wall marks the legendary birth of drawing (Pérez Gómez and Pelletier 1997). Reflecting on a man's shadow and recording the contour of his body denotes a powerful story in which the young woman must face her lover's departure and strive to document him through drawing as an act of memory. In architectural practice, consequently, documentation activities closely adhere to the experience of history. Old buildings and structures constitute the tangible evidence of the past, which allow us to "get in touch with history" (Barthel-Bouchier 1996, 2). They are important "for their characteristics and features, as well as for their association with people and events (Burns 2004b, 8)." Furthermore, in a time when neglect, war, natural disasters, and uncontrolled urban development cause the catastrophic loss of cultural heritage, documentation becomes central to provide information for future generations of structures that have vanished. Documentation transmits the knowledge of the historic environment; therefore "can help keep the heritage from being destroyed or forgotten, and it serves to communicate, not only to conservation professionals but to the public at large, the character, value and significance of heritage" (LeBlanc and Eppich 2005, 6).

For centuries, two-dimensional measured drawings have been the recognized product of architectural documentation, which architects, builders, and scholars have trusted to learn about the built environment, to develop ideas about architectural design, and to disseminate heritage information (Lyn and Dulaney 2009). Measured drawings are line drawings that portray the existing conditions of a three-dimensional structure or a site in two-dimensions through plans, sections, and elevations (Burns 2004a, 88). These documents resemble "as-built" 
architectural drawings in context as the latter are modified construction drawings that are produced immediately after construction. This aside, measured drawings are generally a historical tool made many years after a structure was built, demonstrating the existing condition of a building at the time of documentation rather than its original condition. Documenters carefully observe the material condition of the vestige, interpret the components that make up the architectural heritage, gather measurements from the surface, and then translate these field notes to measured drawings. Each drafted line in a drawing, therefore, represents a cluster of measured points on an architectural element, such as a rosette or a floor panel, which are transposed to a horizontal or a vertical plane to compile plans, sections, and elevations. Mirroring the existing conditions of the built environment through two-dimensional commensurable mediums acts as insurance for any future alterations or damages to the historic architecture. The measured drawings, then, become the point-of-reference records for any type of historic preservation project, for repairing a historic material, restoring the building to an earlier phase, or reconstructing an architectural element if needed.

Suffice to say, there is a temptation to think of the production of measured drawings from survey data as simply a technique of basic visualization of the built environment. Quite the reverse, the systematic basis required by architectural documentation assures a logical approach to illuminate the context in a scale that goes beyond the capture of the physical appearance of existing architecture in metric form. Deconstructing the architectural fabric in the form of two-dimensional illustrations compels the documenters to condense the architectural details of the built environment, like the operational scheme of a building, collective qualities of a cluster of buildings, and development of the architectural space while reflecting on the social nuances that engage the spatial qualities. Documentation of the architectural fabric, in this vein, demands identification and evaluation of the norms, traditions, meanings, and values embodied in the heritage environment. Thus documenters work in the natural setting of a historic structure, spend time in the field from a couple of days to many weeks exploring the nuances and complexities embedded in the architecture that operate over time, and then rendering the cultural context that has reflected in the built environment through measured drawings.

A second temptation exists to overlook the element of interpretation in architectural documentation in a field that is heavily mediated through digital means. To acquire the rich details present in the built environment at a greater extent, documenters increasingly use cutting edge recording and documentation methodologies (Louden and Hughes 2005; Özkut 2008; Akboy and Thys-Şenocak 2009; Warden 2009; Akboy 2011; Akboy-ilk 2013; Akboy-illk 2016). Digital strategies allow the professionals to achieve high-density data from the architectural surface and to translate the field data into measured drawings through the use of the state-of-the-art hardware and software packages. The raw metric field data provides an accurate mathematical representation of the architecture yet is not sufficient to achieve an informed understanding of the cultural heritage. To elicit all values and meanings embedded in the structure, documenters conduct an informed field survey, assembling the knowledge with them to bring out the essential characteristics of the architectural setting through measured drawings. These drawings, subsequently, would foster a deeper understanding of the heritage environment by bridging the historical details and architectural features, with cultural inquiries. Lavoie cautiously stated that engaging the practice of documenting with conventional methodology of handmeasuring and drawing aims to produce a record of the architectural form and character of the historic fabric, which often "overshadowed of conflated with tools for new building construction and management, or the conservation of building materials." $(2011,186)$

The process of analyzing, interpreting, and then depicting the cultural heritage through measured drawings carries significant traits with what Clifford Geertz (1973, 3-30) termed "thick description" in anthropological studies. The practice of thick description is a way to postulate the cultural context and meanings that people assign to actions, objects, words, etc. The inquirer articulates the context in such a detailed way that, any individual outside the culture can make meaning of the subject. Understanding a culture renders the people accessible within the inexplicit terrain of everyday social interactions and dissolves the opacity of the nuances and complexities of actions, behaviors, and events. The cultural analysis presents such a vivid picture that it brings the readers "in touch with the lives of strangers" (Geertz 1973, 16) as well as the architectural environment like in a house a palace, or a sanctuary, which is a collective practice of the culture.

Thick description is a recognized research strategy, "not for large-scale anthropological interpretations of whole societies or civilizations," but for the quest of "microscopic" particulars and meanings (Geertz $1973,21)$. Subsequently, thick description has been often utilized in cultural heritage studies to explore intangible qualities of the historic environment, such as funerary customs, dance rituals, oral traditions, etc. (Schmitt 2008; Kole 2010; Hua and Yujie 2014). In architectural research, there have been several attempts to introduce an application of thick description, for instance, the understanding of the social act of design through narratives of architects' and their clients' (Cuff 1991) and the analysis of urban planning policies through reading the underlying dynamics of neighborhood and community (Jacobs 1961). These examples aside, reflecting on the production of measured drawings as a methodological process of thick description that is informative, enlightening, transformative, and interpretive still remains to be thoroughly explored in the literature.

Geertz's account of thick description focuses on understanding the social action, in other words, human beings. The gist of architectural documentation activity, in this context, includes the built environment interwoven with the patterns of lives and rudiments of civilization. The measured drawings, hence, provide an infrastructure to understand the architectural setting but also are mediums to celebrate the cultural context that has developed the architecture. The production of drawing is a process where documenters continuously strive to determine cultural signifiers internalized in the architectural examples. In an effort to discuss architectural documentation through the lens of thick description, this article is organized in two sections. The first section, Interpretive Thick Measured Drawings, delves into the components of a measured drawing and how documenters present the essence 
of architectural heritage in these mediums. The second section, Thick Drawings in the Documentation Fieldwork, discusses the role of field investigation in architectural documentation and focuses on diverse surveying practices as a means to engage thick descriptive drawings. In this section only hand recording, photogrammetry, three-dimensional laser scanning are being discussed due to the physical limitations of the article. Similar discussions can be extended to other surveying methodologies.

\section{INTERPRETIVE THICK MEASURED DRAWINGS}

Geertz sought to emphasize the significance of analysis along with interpretation in thick descriptive studies and observed that "analysis is... sorting out the structures of signification... and determining their social ground and import." $(1973,9)$ Interpretation, in this context, is the basis for analysis. Ethnographers construct a body of knowledge through a web of data gathering strategies in the field such as interviewing informants, observing rituals, and eliciting kin terms, and then construct a reading of the culture interpreting the meanings embedded in the social actions. Inquirers, traditionally, render the "multiplicity of complex conceptual structures, many of them superimposed upon or knotted into one another" (Geertz 1973, 10) through inscribing textual material, usually a written discourse or a field journal. The inscription transforms the social activity from the terrain of a momentary event to an account that can be accessed for further analysis and interpretation.

In documentation, consequently, a divide exists between how textual and graphic modalities communicate architectural heritage information. Burns stated the graphic content as the major representation tool to communicate the built environment, "a fundamental principle of architectural and engineering documentation is that historic structures cannot be recorded and explained adequately by words." (2004b, 9) Even though reports and written sequence of descriptors typically accompany the documentation project to provide the historic context, a carefully produced measured drawing set may quickly and accurately reveal the physical relationship of the building components (Bopp, 2014). Documenters identify a building component or a set of conditions in the architectural environment and curate unique pieces of information of the edifice in the form of measured drawings. The section drawing of the Asa Packer Mansion in Jim Thorpe, Pennsylvania (Figure 1), for instance, conveys the richly detailed materials and furnishings of a high style Victorian living in the U.S. The Italianate villa was constructed in 1852 subsequent to the mining boom in mid-19th century, followed by major addition in 1878. The sectional analysis of the mansion includes the vertical organization of the spaces of the consequent floors of the house accompanied with the meticulous depiction of the intricate woodwork.

The Asa Packer Mansion was listed in the National Register of Historic Places (NRHP) in 1974 and further became a National Historic Landmark (NHL) in 1985. NRHP is the U.S.'s official inventory of historic properties (objects, buildings, structures, districts, and sites) that deemed significant in American history, architecture, archaeology, engineering, and culture, while NHL is the official list of historic properties for their outstanding historical significance. Both programs are maintained by National Park Service (NPS). Listing on the NRHP or NHL certifies that a property possesses significance, mandates its consideration in the

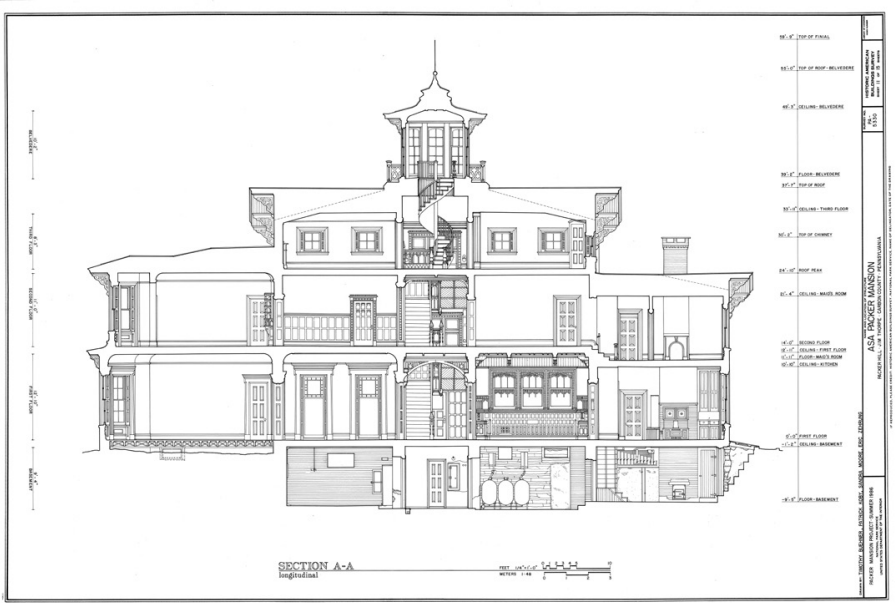

Figure 1. The section drawing of the Asa Packer Mansion, in Jim Thorpe, Pennsylvania, U.S. renders the architectural qualities of the historic house projected into a vertical plane (Library of Congress, HABS PA, 13-JIMTH, 7- (sheet 11 of 15), delineated by Timothy Buehner, Patrick Koby, Sandra Moore, and Eric Zehrung).

planning of federal or federally assisted projects, and qualifies it for federal tax benefits and preservation grant assistance (Fowler 2003: 3580 ). The measured drawing set is not a requirement for the nomination package due to time and budget constrains. Field drawings accompany the nomination form along with textual material and photographs. Documenters include the measured drawing set if available. The architectural description written in support for the NRHP nomination serves to elicit the physical qualities of the mansion, capturing the details of the interior of the house with these lines:

The entire interior is in excellent condition: all furnishings, woodwork, draperies, wallpaper, and carpets, are original, with a very few exceptions. The fine, elaborately carved woodwork on the first floor was done by imported Swiss and Italian craftsmen. The first floor of the mansion consists of parlors, a dining room, and kitchens. The second and the third floors contain guest and servants' quarters... Entry into the center hallway from the west parlor, introduces one to the fabulous carvings in wood carried out by European artisans... The gothic motif, used throughout, is done in oak in the hall, and contains some 5,000 rosettes, each with a slight difference. In keeping with the gothic motif is a grand- father clock with turrets and arches next to the west parlor entrance. The lattice-patterned rug of red wool, in the hall, is also used on the stairs, and it is this pattern that lifts the eye from the first level to the stained- glass windows at the stair landing... Just off the hall to the east, the northlight from the stained-glass windows of the dining room floods the room with an exciting, dramatic light. At night the gas chandeliers, now electrified, produce a pleasant alternative to the stained-glass window light... (Pitts 1984: 2-3)

This script constitutes an example to what Denzin (2001: 102-106) refers as "thin description" in social sciences. Thin description is stating facts 
without such meaning or significance. Statistical tests, questionnaire surveys, summary statements to theorize the field findings are some examples of thin description. The architectural description of the mansion, hence, probes facts about the basic architectural qualities of the building which meets the technical needs of a NRHP nomination form. The text takes the readers from one room to another and provides basic information on the make and design of the woodwork as well as the furnishings, such as the lattice patterned rug and stained glass windows. Visualizing the architectural space based on this text may raise difficulties for the readers unless they have specific knowledge on the design, materials, and construction details of the peer Italianate villas in the U.S.

Measured drawings, on the contrary, provide richly detailed graphical representation of the architectural setting, which allows the viewers "get their eye in" the structure (Wickstead 2008: 15). The section drawing, for instance, is an imaginary vertical cut through the structure, which reveals the vertical progression of spaces accompanied with structural details, interior decorative finishes, and relation of functions. Documenters determine the precise location of the cut line in order to provide maximum information and the judgment of the probing the cut line is a professional skill that only comes with practice (Woodcock 2006). In the section drawing of the mansion (Figure 1), documenters promote the vertical sequence of the spaces captured in the NRHP nomination form and amplify the architectural qualities through the aforementioned spaces such as the west parlor, entrance hall, dining room, kitchen on the first floor as well as the bedrooms on the second and third floor while revealing the intricate wood detailing. The advantage of this type of graphical thick description includes the facilitation of a higher level of understanding of the mansion by providing an index of information and "lived-in" condition at the time of documentation. The section drawing takes the viewers inside the mansion and provides a view of how one would operate within the house walking under the bracketed ceiling woodwork with its intricate carvings or gazing at the transverse arches in the entrance hall.

The two-dimensional reconstruction of architectural heritage necessitates that documenters dissolve the opacity of the edifice through presenting building elements in a graphical form that can be further studied and interpreted. During documentation work, consequently, documenters mentally peel away layers of alterations made in the historic setting along with the architectural "subtractions" (Belardi 2014, 73). Doing so, they determine the essential components of the architectural environment and communicate the framework within they would operate their inquiries. They begin interpreting architectural elements that signify the cultural asset (the spatial layout of the building, craftsmanship of the woodwork, vertical progression of spaces, etc.) and determine the gist of the measured drawings (depiction of the staircase, location of the section cut line, development of detailed-drawings, etc.) accordingly. Amplifying certain architectural qualities does not mean that documenters have neglected some aspects of the heritage context; on the contrary, they interpret that some details are more significant to convey the architecture's relationship to the cultural heritage.

Measured drawings as a medium of interpreting the architectural fabric transcends their significance as mere illustrations of building forms and styles. Plan drawings, for instance, capture patterns and rudiments that reveal the lifestyle and folkways of the past. Section drawings and axonometric perspectives are crucial to reflect a certain process, use, or function, which is difficult to observe with the naked eye (Lavoie 2011). The plan drawing of the Seward Plantation Slave Quarters, built c.1855 in Independence, Texas, U.S. (Figure 2), depicts a two-room dwelling in a Southern plantation, which was listed on the NRHP in 2013. The structure is a one-storey cedar log building with a gable roof supported by a field stone foundation. Documenters in this drawing provide a technical representation of the partially collapsed structure. Utilizing an imaginary horizontal section cut through the structure exposing walls, door and window openings, and hearths, they meticulously render the existing building components. The effectiveness of this measured drawing, however, stems from its ability to resonate the spatial organization of the social structure of the time.

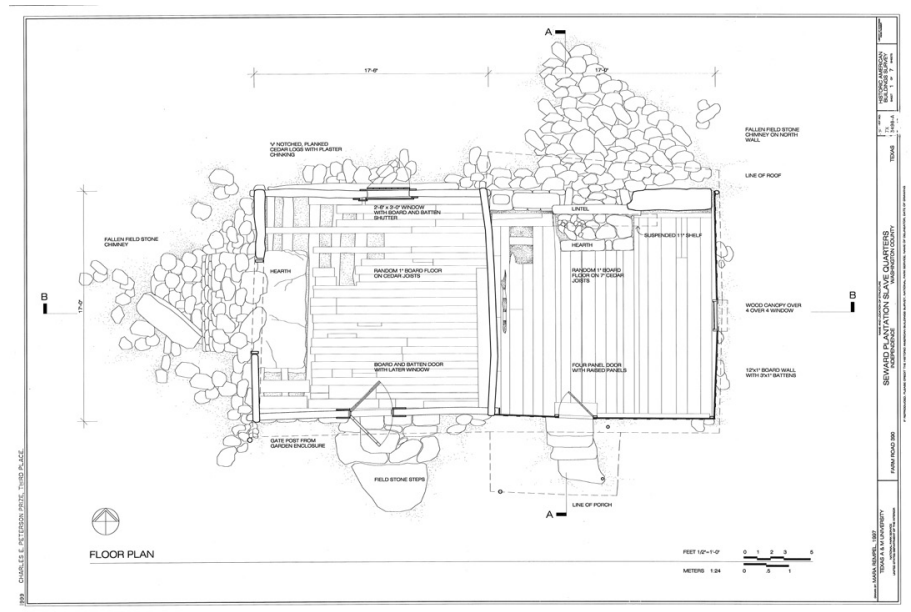

Figure 2. The plan drawing of the Slave Quarters in the Seward Plantation, Independence, Texas, U.S. shows that the dwelling meant for little more than sleeping for the inhabitants (Library of Congress, HABS TEX, 239-INDEP, 9A- (sheet 1 of 7), delineated by Mara Rempel).

The plan drawing ties the functionality of the structure to 19th century recreational segregation in a plantation landscape. The dwelling is in fact a duplex, where single-room units share a common wall and have their own exterior entrance, window, and hearth. The discrete units without internal passages and separate entrances suggest that this was not an instance of enlarging the structure to accommodate a growing family but rather adding space for an additional family (Fisher 2012). It was habitual to witness the day-to-day life activities of living, dining, and sleeping carried out in each unit. What is particular about the plan drawing is the reflection on the daily accommodations in each unit. The footprint of the garden enclosure around the house indicates that the families owned a small plot of land to grow things to supplement their diet. After a workday in the cotton fields, the families would pass the garden, walk through the porch, and enter the dwelling using the bare field stone steps depicted in the drawing. Inside the unit, they would fashion a private life for themselves, maintaining daily activities of caring for kids, preparing dinner, and washing. 
The hearths located in each unit were an integral part of the dwelling, which were used for heating the dwelling and cooking food. After the daily chores, the members would lay down around the hearth and sleep communally. The shelves around the hearths were used to store house items as well as personal belongings. At the time of documentation, both chimneys were partially collapsed and piles of debris were laying around the units. Albeit the dilapidated condition of the hearths, documenters' recognition of the significance of these structural elements culminated in a detailed graphical description in the plan drawing (Figure 2). From the depiction of the standing chimneys to the portrayal of each field stone in the piles of debris and to the delineation of the remaining shelves on the walls connote the importance of the hearths in the lives of the inhabitants.

Measured drawings resemble the ethnographic written material through thickly describing and presenting a graphical architectural representation that can be interpreted. Documenters, hence, are tasked with conveying as much information as possible from the physical entity efficiently and accurately to deliver a more comprehensive record of the architectural setting. Besides reconstructing the architecture through formal measured drawings (plans, sections, and elevations), documenters often employ interpretive drawings to render non-traditional or intangible values associated with the heritage setting (circulation pattern, evolutionary change, particular movement, etc.). Tompkins et al. (2004) wrote that some characteristics of the historic structure may be found in the evolution of a site over time or some structural features are not apparent from the edifice's exterior. In these cases, documenters extract data from the field notes as well as the measured drawing set and curate them to provide a recognizable depiction of the significant feature of the architectural environment.

An interpretive drawing cross-references and integrates material by putting together details that may otherwise appear separately in accompanying written data, photographs, or standard measured drawings. Interpretive drawings help the user to see significant relationships and features impossible to present effectively with other documentary media. Characteristics that invite this treatment may be structural details, a manufacturing or materials-handling process, the organization of machinery or other elements within a building or site, or the operative principles behind a particular engineering device or system. Interpretive drawings should be made when no other type of presentation is as efficient in terms of content conveyed, cost to produce, or time required for a user to study. (166)

A drawing sheet of isometric projections (Figure 3) compiled for the Greek-Revival style Giddings-Wilkin House, Brenham, Texas, U.S., exemplifies an interpretive drawing. When documenters set to record the house built in 1843, they recognized that its two-storey configuration, flat roof, and Greek-Revival appearance would not have been used at the time of the young Republic of Texas (18361946); these architectural characteristics indicated a much later date. Therefore, to fully understand and describe the significance of the house, documenters began exploring the sequence of the changes made to the building. Guided with archival research and the Giddings family letters, documenters were able to identify additions, alterations, and demolitions in the prevailing architectural surfaces. Careful measuring and analyzing of the wooden boards in the hallway and front parlor, for example, confirmed that the location of the doors were changed to accommodate the room additions in the rear (Woodcock, 2006). Documenters identified the tapestry of architectural spaces assembled from 1843 to 1990, and rendered isometric projections to demonstrate when each extension and/or remodelling took place. Figure 3, hence, maps the historical development of the house, which is otherwise difficult to trace with the naked eye.

The young Jabez Deming Giddings built this house as a two-room dogtrot with an upper sleeping loft. To accompany the needs of his growing family, the house was subsequently expanded between 1860 and 1872; bay windows and front porch on the first floor, and a kitchen and rooms attached in the rear. The Greek-Revival style architectural details were, in fact, introduced to the house during the expansion circa 1860, when the front porch was constructed, first floor ceilings elevated eleven feet, and full second floor with a flat roof added. While remodelling, Giddings, most plausibly, pursued the growing interest in the nation for the Greek-Revival architecture. Much of the first half of the 19th century, in the U.S., the simplicity and dignity of the Greek architectural forms and elements were broadly adapted for a young country with limited means but with needs for refined architecture (Hamlin 1944: 213-233). Architectural models evocative of Greek democracy were considered appropriate in the new republic, rejecting traditional ties to England (McAlester, 2015). Even the modest frame houses, such as the Giddings-Wilkin home, would be introduced a few classic details, such as a cornice, capped posts on the porches, and multi-paned double-hung sash windows. These architectural forms and details were extensively circulated through heavily illustrated pattern books and folio volumes, upon which builders such as Giddings freely adapted to the climatic needs and the available local materials.

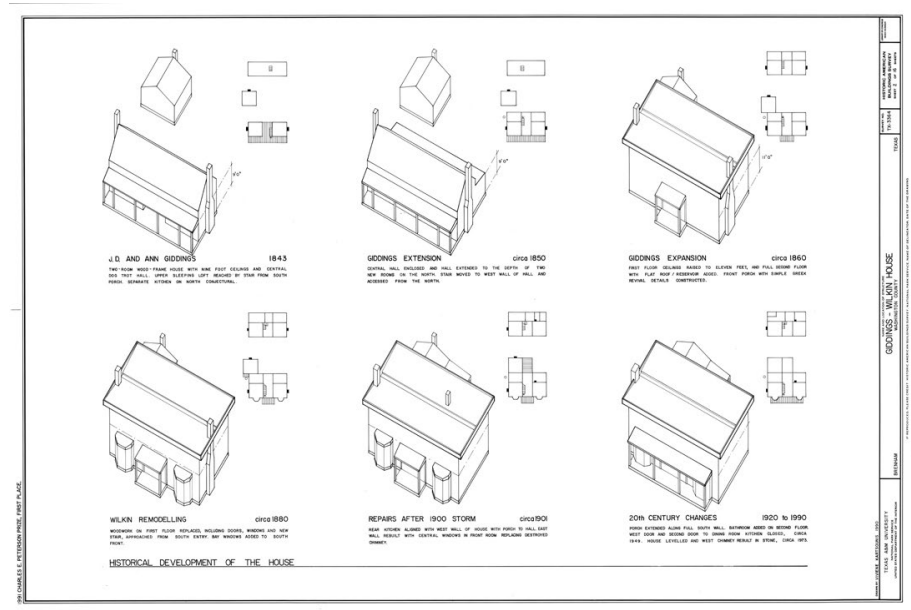

Figure 3. The isometric projections of the Giddings-Wilkin House, Brenham, Texas, U.S. demonstrates the historical development of the architecture (Library of Congress, HABS TEX, 239-BREN, 2- (sheet 2 of 16), delineated by Viviene Kartsounis). 


\section{THICK DRAWINGS IN THE DOCUMENTATION FIELDWORK Field Investigation}

Geertz advocated that human social life includes meaningful activities very imperfectly studied through the objectifying methods of certain kinds of sciences (Ortner 1999). He constructed the interpretive approach against the variety of reductionist and objectivist work dominating the social sciences in the 1950s. Then-ascendant universal theories and deterministic models were extensively employed to account human behavior, which Geertz firmly detested and declared that "If you want a good rule-of-thumb generalization from anthropology, I would suggest the following: Any sentence that begins, 'All societies have...' is either baseless or banal," Geertz $(2000,135)$. Instead, he sought an intellectual framework that prioritized the roles of symbols in constructing public meaning. The ethnographic texts, accordingly, would enable conversation across societal lines, of ethnicity, religion, class, gender, language and race.

The webs of meaning embedded in social activities could only be understood through acts of interpretation, analogous to the work of literary critics (Ortner 1999). Geertz interpreted ethnographic work as constructing a reading of a manuscript that is "foreign, faded, full of ellipses, incoherencies, suspicious emendations, and tendentious commentaries," (Geertz 1973, 10). Ethnographers' task includes capturing the ephemeral examples of shaped behaviour. Thus, the heart of Geertz's philosophy includes the ethnographic fieldwork as the "locus of study is not the object of study," meaning that "Anthropologists don't study villages (tribes, towns, neighborhoods...); they study in villages" (Geertz 1973, 22). The act of writing is deeply intertwined with observing, recording, and analysing the conception of the matter. This knowledge-seeking process constitutes a logical reconstruction "of the crystal significance purified of the material complexity" (Geertz 1973, 20). In his writings, he also acknowledged that ethnography is inherent in different mediums such as drawings, films, photographs, etc., but these modes of representation remains to be methodically explicated through the lens of thick description (Geertz 1973).

Ethnographers often utilize the act of drawing as well as the product as an anthropological research method, in order to interpret the cultural forms. The act of knowing, seeing, and then documenting through drawing provides inquirers a methodological process similar to that of ethnographic textual material (Bray 2015). Anthropologists including Evans-Pritchard (1940), Lévi-Strauss (1963), and Malinowski (2014) have used drawings as well as paintings as part of their research methodology and utilize two-dimensional graphical mediums to accompany their ethnographic writings. Today, anthropologists have addressed the significance of drawing in their studies (Hendrickson 2008; Nakashima Degarrod 2010; Taussig 2010; Causey 2012). Taussig (2010), for example, advocated that drawing allows him to develop more intimacy with the subject being depicted, as "drawing tends to be a mute conversation with the thing drawn and can involve prolonged and total immersion." (172) Similarly, Hendrickson (2008) stressed that drawing is "a field-based, generative process that engages [ethnographers], simultaneously, in the acts of thinking, seeing, and doing." (117) Drawing in fact enables the inquirers to grasp and render many qualities of the ethnographic material, such as texture, emotional climates, and experiences, which cannot be represented in texts (Nakashima Degarrod 2010). Paintings, subsequently, serve better to depict the visual nature of the emotional aspects of ethnographic data. Given this, Causey (2012) wrote that making drawings of his environment enabled him to pursue a reflexive analysis "to gather data unobtainable otherwise" (162) during the fieldwork.

In architectural documentation, making drawings of the built environment allows the inquirers to acquire a deeper understanding of the architectural environment (Warden and Woodcock 2005; Woodcock 2006; Lavoie 2010; Akboy 2011; Akboy-illk 2013; Akboy-illk 2016). The documentation analysis requires that the documenters immerse in the context of the built environment, observe the material and structural details in the edifice, record the surface, and then interpret all this data to measured drawings. Figure 4, demonstrates two student architects studying a structural piece from a colonnade among the archaeological remains (ca. 200-1000 C.E.) on the Boğsak Island, Mersin, Turkey in order to produce a detailed drawing of the early Byzantine structural piece. Warden and Woodcock (2005) touted the significance of drawing in architectural documentation as a self-exploratory process to understand the reality of the historic setting. The process constitutes a link between the hand, the eye, and the brain in which documenters mediate in the architectural setting with a focused acknowledgement of the particular place, being attentive to all the elements that make up the cultural heritage.

[Drawing] requires time, judgment, and interpretation. The sketch rarely emerges perfectly but is massaged and reworked many times, with success measured against the norm of the building. That norm is also virtual in nature, because a true elevation experience is impossible. The person making the sketch must constantly reconcile abstract differences between the building and the sketch and this process forces the sketcher to engage the building through questions pertaining to dimension, proportion, and scale. (Warden and Woodcock 2005: 113)

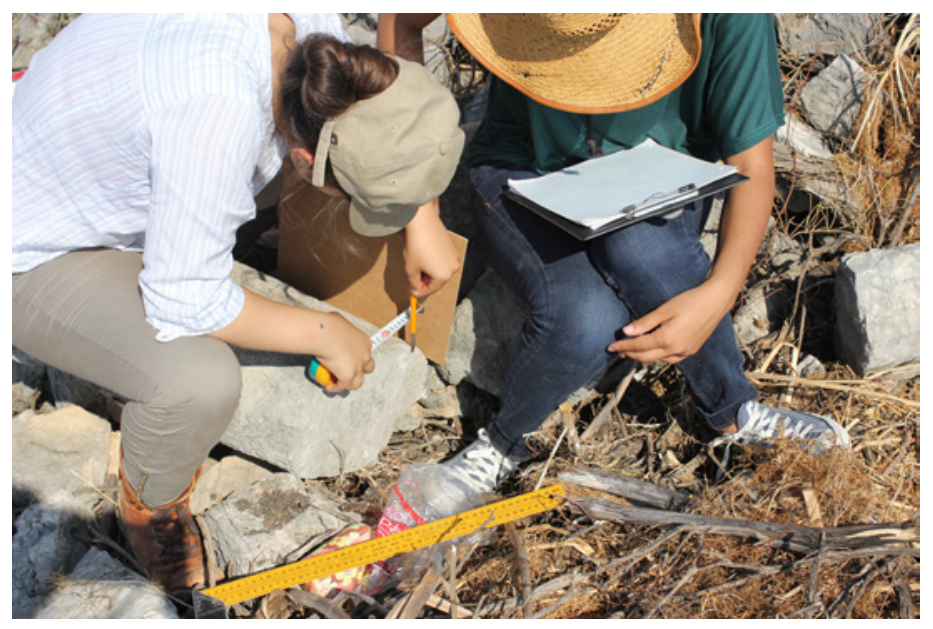

Figure 4. Documenters measuring and drawing a structural piece from a colonnade during the Boğsak Archaeological Survey, Mersin, Turkey, photograph taken by the author, 2013. (Courtesy of BOGA) 
Documenters' immersion in the heritage environment is fundamental for investigating and interpreting social nuances in the measured drawings. When documenters set out to document Montezuma Castle, Camp Verde, Arizona, U.S., a cliff dwelling habitat constructed by Sinagua people of Arizona's Verde Valley in the late 12th century A.D., dissecting the architectural forms through plans, sections, and elevations became the initial response to capture the spatial layout of the dwelling perched some fifty feet above the valley floor. The five-storey stone structure was built to make it difficult for enemy tribes to penetrate the natural defense of the vertical barrier. As Sinaguas reached specific levels, the ladders were pulled-up behind them until reaching the safety of community rooms. Building a dwelling so elevated from the ground afforded defense against other humans but also allowed the inhabitants to escape the natural disasters such as the annual flooding of Beaver Creek. During the documentation fieldwork documenters scaled up the cliff with portable ladders to reach the structure, following the daily experience of the Sinagua people. Once inside the castle, documenters accessed upper floors using ladders penetrating through openings in the ceiling. Closer attention to the circulation patterns through five floors culminated in documenters' emphasis on the depiction of vertical paths as the heart of this structure. Deconstructing the consequent levels with a sequence of vertical section cuts (Figure 5), thus, allowed the documenters to explain the circulation system used in the dwelling 800 years ago. This longitudinal section emphasizes the vertical connection between Level 1, 2, and 3 of the castle, respectively the storage rooms in the basement area and living quarters located in the upper floors. In the drawing, the small keyhole doors between the rooms in the upper levels are visible, but the main means of communicating between the rooms and terraces were by ladders and roof hatches.

While documenters continued their quest inside the cliff dwelling recording the chambers, they began to reflect on structural elements. The interior of the castle remains almost completely intact, with many of the original ceiling support beams and logs still in place, and various layers of mud plastering over the stonewalls. One of the most remarkable

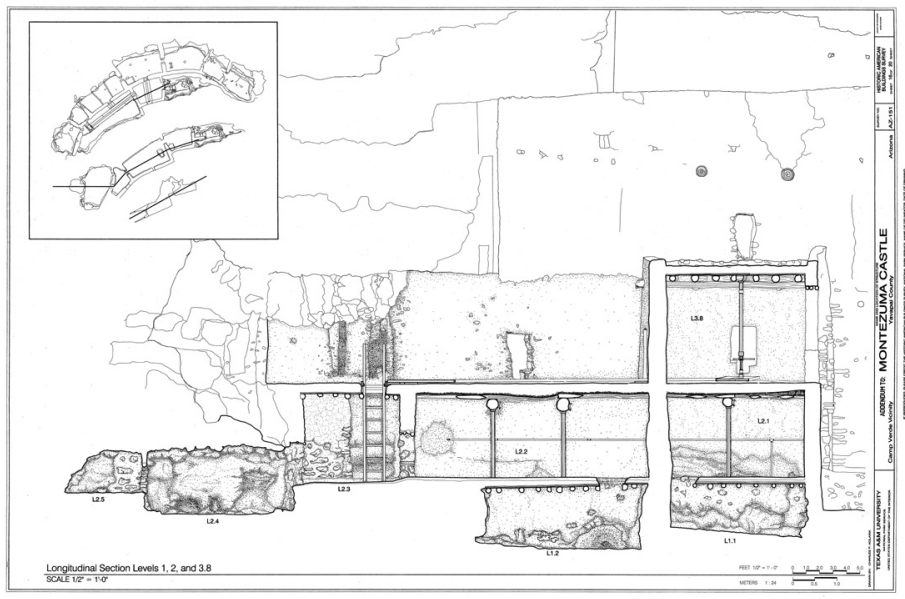

Figure 5. The section drawing of the Montezuma Castle, Camp Verde, Arizona, U.S. articulates the vertical circulation pattern in the dwelling (Library of Congress, HABS ARIZ,13-CAMV.V,1- (sheet 16 of 20), delineated by Charles P. Kolarik). things about the walls was the lack of pictographs and petroglyphs, which was inconsistent with the extensive artwork of other Sinagua sites in the area. The only archaeological survey conducted for Montezuma Castle in 1988 stated that the dwelling lacked the wall painting and markings that could only be explained away by the difference in local materials and construction technique. Therefore, in the process of making measured drawings, documenters were forced to pay close attention to the walls (Warden and Al Ratrout 2005). Further analysis of the walls revealed that, in fact, Sinaguas at Montezuma Castle were not that much "quieter" with their art than their neighbors (Warden and Al Ratrout, 2005: 2). The inhabitants continuously rendered images and symbols on the walls to express their feelings and thoughts. The markings on the walls were so subtle, however, they were impossible to detect with the low light level in the rooms. Documenters, therefore, employed different lighting techniques in search for new markings. The walls, subsequently, revealed a rich collection of subtle textures, which contain much information about the Sinagua construction techniques, their artwork, and later Anglo graffiti. Documenters' efforts on dissecting the monumental cliff dwelling through plans, sections, and elevations, accordingly, extended to include further detailed drawings of the markings. Figure 6 illustrates one of the drawing sheets dedicated to the markings. What is revelatory of these graphical inscriptions is that they include an important aspect of the Sinagua practices, which has not been recognized before the documentation campaign of the Montezuma Castle. The drawings bring out the level of engagement and connection of Sinagua with material life as well as with their beliefs out of the castle and into public view to be further studied and interpreted.

\section{Utilization of Surveying Technologies}

The surveying methodologies documenters employ during the fieldwork from analog hand measuring to digital three-dimensional surveying mediate the architectural nuances engaged in measured drawings. Each different practice in the act of documentation transforms the methodological path to generate measured drawings, along with the content of the drawings (Akboy 2011; Akboy-ilk 2013). Documenters,

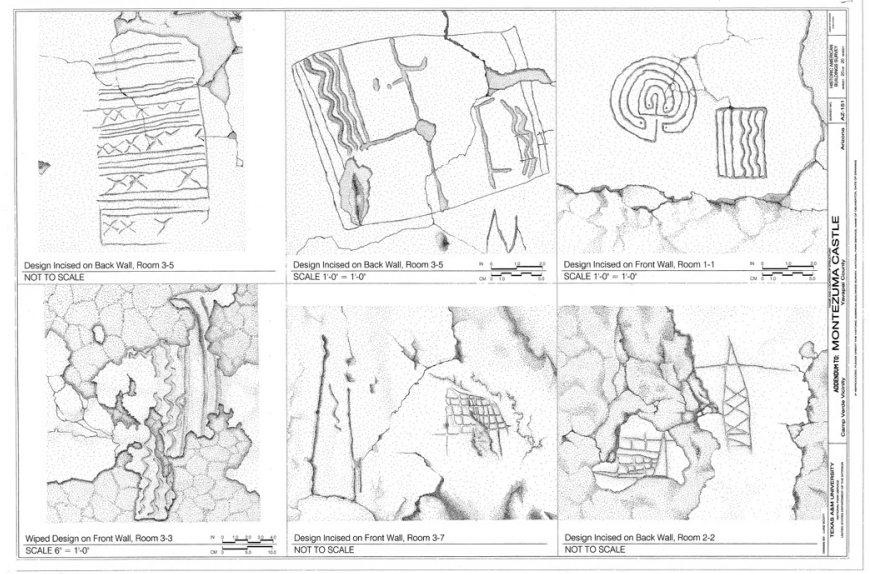

Figure 6. The detailed drawing of the Montezuma Castle, Camp Verde, Arizona, U.S. focuses on the markings and inscriptions on the walls (Library of Congress, HABS ARIZ,13-CAMV.V,1- (sheet 20 of 20), delineated by Luke Scott). 
traditionally, acquire measurements from the architectural surface manually which entails on-site observation and analysis (Figure 4). The field notes include comprehensive dimensions directly collected from the historic surface and accompanying annotations explaining building materials, construction techniques, and subtleties on the materials, etc. For this reason, hand recording remains vital in architectural documentation because it is a very rapid method requiring few tools and minimal training. It often provides sufficient information by which to carry out preservation activities (Bryan 2010). However, hand surveying methods necessitate direct access to the object which can sometimes be difficult to achieve and expensive to facilitate when faced with recording high-level detailing of very large sites or tall structures or irregular formed architectural surfaces (Eppich and Chabbi 2007).

In today's architectural culture much of the documentation process is digitally drafted. Documenters use digital surveying technologies such as photogrammetric tools, and three-dimensional laser scanners to mass capture measurements from the architectural surface. The benefits of these advanced methodologies over hand measuring include extreme accuracy, the ability to record challenging heights and locations remotely, and a potential savings in field time (Louden and Hughes 2005; Warden and Woodcock 2005; Warden 2009; Lavoie 2011; Akboy-ilk 2016). The ability to record historic buildings from a distance while avoiding any need for elaborate scaffolding, cranes, or climbing gear, furthermore, generates a safer working environment for the documenters with less possible field hazards. Recording derelict buildings or unoccupied structures meters away allows documenters circumvent any physical exposure with rotten floorboards, upstanding nails, and staircases that will not support weight, or asbestos, mold and fungus, which is often present in historic structures. To gather mass measurements, besides, considerably mitigates the cost of the fieldwork since documenters can undertake a building survey in a couple of days fieldwork compared to weeks long hand measuring. The exactitude of the digital data is also useful when tackling any form of a preservation project, subsequently it serves diverse purposes, the data set for the measured drawings, the volumetric measurements for detecting a deflection in a wall, or metric information for monitoring cracks in roof trusses. Collecting reliable data, however, depends on the documenters' knowledge and experience with the surveying technology. If documenters lack the skills in surveying hardware and software, the documentation process becomes difficult to negotiate (Akboy-illk 2013).

The increasing use of advanced technologies in architectural documentation stem from the desire to provide a seamless process of data gathering and production with minimal human intervention in data transcription and translation (Warden and Woodcock 2005). The non-intrusive character of digital tools allows documenters to collect field data without needing to physically access historic structures and to compile the data without having to produce drawings. However, the methodological path of automation of information during architectural documentation carries similar traits to what Geertz critiqued against reductionism and positivist research methods utilized in social sciences, using objectifying methods to generate records of the societies and to explain the underlying historical processes (Ortner 1999; Sewell 1999). Given this, Geertz asserted that human activities cannot be studied through an objectivized stance and instead advocated close readings of the human activities to understand the cultural phenomena. To provide greater authority and accuracy about the findings, researchers have widely employed quantitative techniques as part of their research methodologies, such as spatial technologies (GPS, GIS, threedimensional modelling) in pursuit for archaeological inquiries (Wheatley 2000) or advanced statistical tools to process large quantities of data to understand the cultural components in societies (Shennan 1997). Nevertheless, the automation process to streamline the documentation activity can fail to capture important details in the edifice since the technological mediation does not allow any cognitive hierarchy in interpreting the built environment.

The rigorous use of digital methodologies in documentation corresponds to the need "to overcome the cumbersome analog to digital conversion suggested by traditional design and measuring methods" (Warden and Woodcock 2005, 113). Despite the promise of the digital surveying methodologies to eliminate mistakes in translation of information from data acquisition to production, these advanced applications still require human cognition to read the characteristics of the heritage environment. During fieldwork, documenters are required to monitor how closely the digital data represent real world measurements, to crosscheck the accuracy of the field data and to detect any missing data. For example, a principle disadvantage of the advanced surveying technologies such as photogrammetry or three-dimensional laser scanning is that the architectural features need to be visible in order to be recorded. Elements that are obscured by adjacent features, by excessive foliage, or otherwise beyond the range of the tool are not good candidates for this type of surveying. In photogrammetric work, for instance, the camera filters out all the existing details that exceed its frame. If applicable, documenters have to take more photographs to capture the detailing. The scanner, on the contrary, cannot capture beyond its range such as the tops or undersides of structures (Louden and Hughes 2005; Lavoie 2011). Therefore, during fieldwork, documenters carefully monitor possible voids in the survey data and merge alternate surveying strategies to capture the obstructed views. Cramped conditions on the site or projected elements covering a portion of the structure, furthermore, still require conventional hand recording strategies (Akboy 2011).

Digital surveying methodologies provide a digital image of the architectural surface that documenters tailor to meet the needs of the content of the measured drawings. For example, Figure 7 demonstrates a drawing sheet of the nave windows of the east side of the Gothic-Revival style Saint Andrew's Episcopal Church in Bryan, Texas, U.S., which was constructed during 1912-1914. The detailed drawings of the stained glass windows were generated using photogrammetric data. Photogrammetry is the art and science of acquiring measurements from photographs. The state-of-the-art photogrammetry tools allow documenters to generate three-dimensional models through triangulating mutual points on highquality photographic overlays. Documenters clip appropriate views from the surrogate that represent an architectural element (an arch, a door, or a niche) or an architectural prescription (a plan, a section, or an elevation) and use these slices as templates to trace from, utilizing digital drafting software. A major advantage of the photogrammetry work, the software (PhotoModeler Scanner, Agisoft PhotoScan, etc.) triangulates all the existing dimensions of the architectural element, 
once the documenter assigns a known measurement from point $A$ to $B$ on the surface. This procedure, drastically, reduces the field time to collect measurements from the architectural surface manually, since with couple of critical measurements, documenters retrieve the bulk of the field data to be used as a template for the measured drawings.

Although, useful for vertical surfaces (elevations and sometimes sections) and relatively close-up, straight-on details, very tall structures or large sites hinder the photogrammetric fieldwork. When much of the detailing is too high up from the ground to be photographed or the structure has irregular forms, such as the detailing in the sanctuary of the Saint Andrew's Episcopal Church in Bryan, Texas, access to all the surfaces and taking systematic photographs would bring further logistical

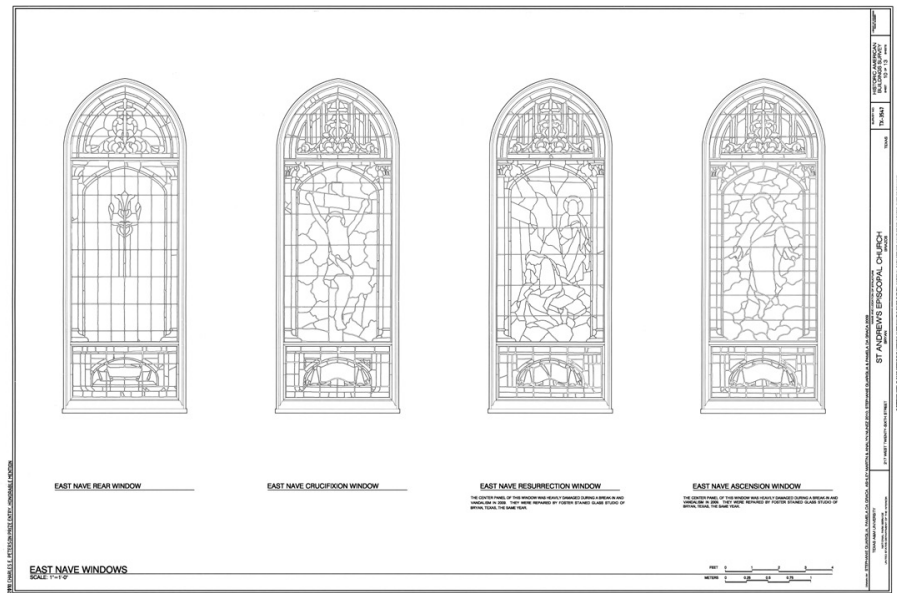

Figure 7. The detailed drawings of the Saint Andrews Episcopal Church, Bryan, Texas, U.S. were generated using photogrammetric data (Library of Congress, HABS TX-3547 (sheet 10 of 13), delineated by Stephanie Guariglia, Pamela da Graca, Ashley Martin, and Analyn Nunez).

issues to the photogrammetric fieldwork. In these cases, documenters prefer alternate surveying practices such as three-dimensional laser scanning to collect measurements from the architectural surface. A laser scanner is a device that mass-captures the three-dimensional data of a subject by use of rapid range measurement. The resultant threedimensional mass is called a "point-cloud." Figure 8, illustrates the pointcloud of the Saint Andrew's Episcopal Church, which includes millions of points with $x, y, z$ Cartesian coordinates, RGB values, reflectivity, and intensity parameters. Documenters clip the three-dimensional pointcloud to represent the desired two-dimensional view such as the plan, section, or elevation, and then meticulously generate the measured drawings. Figure 9, demonstrates the north - south section drawing of the Saint Andrew's Episcopal Church generated using three-dimensional scan data.

Due to the mass-capture of the details on the surfaces through a photogrammetric recording or three-dimensional scanning, documenters can acquire building information with minimal time onsite and then extract this information from the digital surrogate later in more controlled conditions. The computerized field work allows the documenters to process large quantities of digital data as well as to

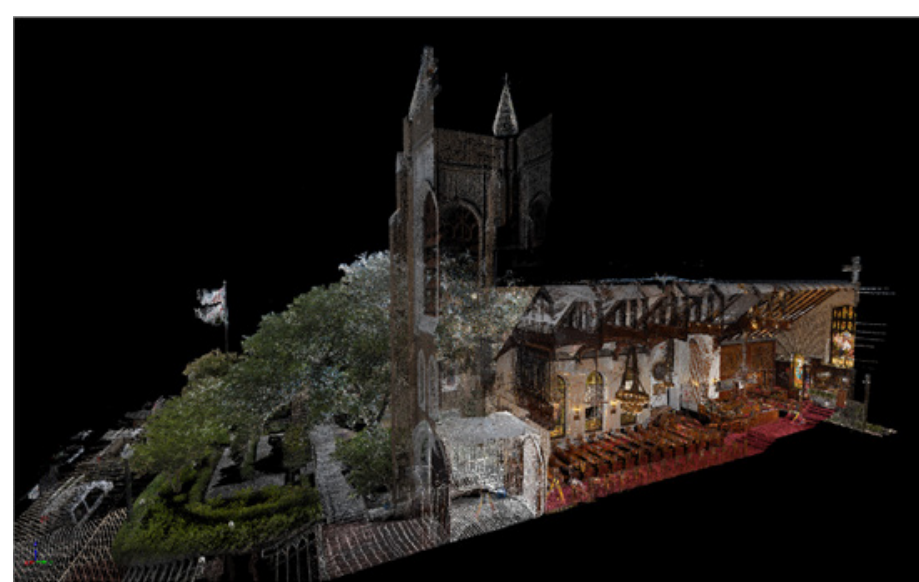

Figure 8. The three-dimensional point-cloud can be "sliced" to generate templates for section drawings such as the three-dimensional scan data of the Saint Andrews Episcopal Church, Bryan, Texas, U.S. The threedimensional model developed by Robert B. Warden. (Courtesy of Center for Heritage Conservation)

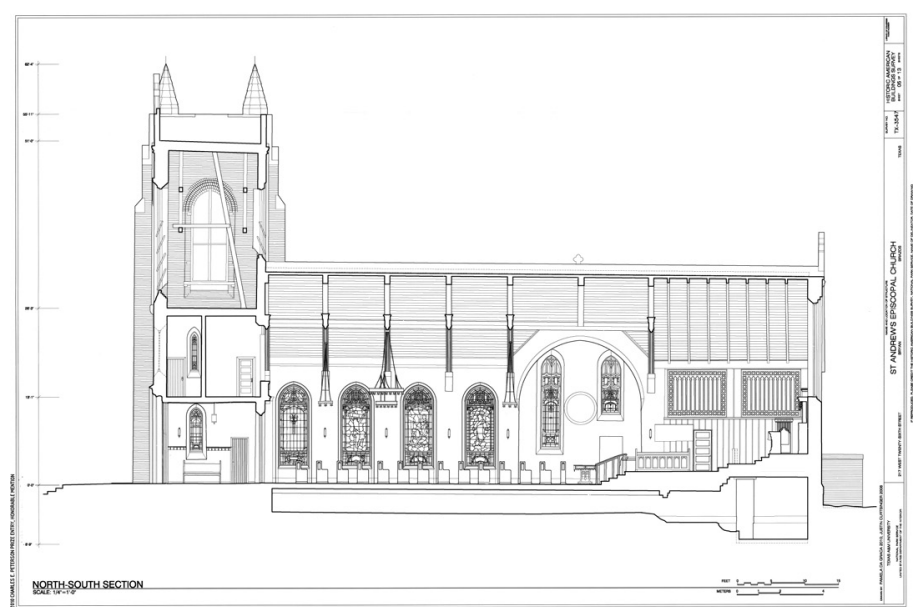

Figure 9. The section drawing of the Saint Andrews Episcopal Church, Bryan, Texas, U.S. was generated using three-dimensional scan data (Library of Congress, HABS TX-3547 (sheet 5 of 13), delineated by Pamela da Graca and Justin Curtsinger).

generate diverse two and three-dimensional products. The automated data collection, however, alienates the path for field investigation as a means of obtaining an informed understanding of the site or structure. The use of digital tools has the pedagogical drawback of separating documenters from direct contact with the material cultural fabric being studied. The operational scheme of remote surveying methodologies discounts the on-site field analysis and observation, which is a requisite to discern the subtleties embedded in the built environment. While photogrammetric work or three-dimensional scanning provides mass quantities of field data, none of these methodologies can distinguish 
details on the type of the building materials or construction systems (Lavoie 2011). Only documenters' close readings of the heritage environment in the field can detect the essential characteristics as well as changes in the historic asset and manifest the type of information (detailing of the woodwork, markings on the walls, circulation patterns, etc.) to be included in the measured drawings.

The three-dimensional models, thus, allow the documenters to present a three-dimensional space, such as the scan data of the Saint Andrew's Episcopal Church (Figure 8), but require little or no interpretation on the part of the inquirers. Documenters can rotate the virtual surrogate to have an overall look of the asset and magnify individual features to acquire metric data, but the model does not include the level of interpretation required to develop a measured drawing. The making of measured drawings necessitates documenters reducing "sites and structures to their essential form, void of color and other distractions, utilizing elements such as line weights, shadowing, and perspective to enhance the clarity of vision," (Lavoie 2011, 188) yet they add detailed texture, ornamentation, and weathering information in the measured drawings that mark the architectural context. For example, the section drawing of the Saint Andrew's Episcopal Church (Figure 9) compiles the vertical arrangement of spaces and the interior details that are complicated to follow in the three-dimensional point-cloud. The surfaces correspond to the cutting plane emphasized with a darker shade of line amplify construction details, like the dimensions of the wooden beams, the thickness of the walls, and the profiles of the wood ornamentation. Behind the cutting plane, documenters delineated the details in the building with a lighter shade of lines. The viewers can follow the architectural qualities from the entrance of the church building with the castle-like towers and parapets, to the stained-glass windows adorning the rows of seats, and to the intricate woodwork progressing to the altar.

\section{CONCLUSION AND FUTURE RESEARCH}

The analytic practice of thick description goes beyond recording mere facts and surface appearances. Geertz's approach of thickly describing a social scene provides a written reenactment for the readers to experience the events being described. Interpretation is the backbone of this level of conceptualization of the social phenomena, meaning that "a good interpretation of anything, a poem, a person, a history, a ritual, an institution, a society, takes us into the heart of that of which it is the interpretation" (Geertz 1973, 18). Architectural documentation contributes to this enterprise through providing rich heritage information that lays the groundwork for "thick interpretation" (Denzin 2001, 117). The thick descriptive work of architectural documentation brings documenters to an understanding of the built environment that created the conditions for the existing context. Documenters' interpretation on the architecture's past and current condition through two-dimensional measured drawings allow them to present an architectural form that makes the essence of the cultural heritage available to today's audience.

The rich heritage information embedded in the drawings is the result of documenters' interpretation of the cultural asset. Either recording and interpreting the prevailing architectural qualities in the form of plans, sections, and elevations, or explicating hidden, missing, intangible, or partly available qualities of the heritage setting through interpretive drawings, documenters "inscribe" a graphical text contextualizing the essence of the cultural heritage. The thick drawings mediate a comprehensive record of the heritage context and elevate the perceptual approach to the architectural qualities. These graphical mediums act as a fragment of information, representing a special place in time and space as a survivor of the past. Documenters' curatorial selection of the meaningful elements from the architectural surface and means of representation include a clear statement of the significance of architectural heritage. The emphasis on the woodwork in the section drawing of the Asa Packer Mansion (Figure 1) or the amplification of the stained glass windows in the detailed drawings of the Saint Andrew's Episcopal Church (Figure 7) translate the architectural context into a thickly described analytical account, which brings an exceptional level of interpretation to heritage information.

Surveying technologies such as photogrammetry recording and threedimensional laser scanning aid documenters to compile an accurate record of the cultural heritage. These methodologies, however, result in a certain level of detachment with the built environment, which is essential for field investigation. In order to interpret the cultural forms embedded in the built environment, documenters traditionally engage with the heritage setting while observing, analyzing, and recording the architectural components. As in the case of the documentation of the Montezuma Castle, documenters' careful investigation of the architectural surfaces led to acquiring an understanding of the wall art of Sinagua people (Figure 6). Likewise, the weathering information embedded in the floor boards of the Slave Quarters (Figure 2) can only be exposed through documenters' intimate awareness to the spatial qualities. Neither photogrammetric data nor three-dimensional pointcloud can substitute the human cognition of the built environment that is reflected through on-site analysis, interpretation, and observation.

Drawing, hence, is extremely descriptive and critical to acquire an understanding of the intention of the building's purpose as well as the essential characters of the built environment. A three-dimensional virtual model of the Saint Andrew's Episcopal Church building (Figure 8) provides documenters a powerful mathematical representation of the physical space, which users can rotate, zoom individual details, etc. Yet, if the viewers lack knowledge on the inherent qualities of the historic asset, it would be difficult to interpret the material. A drawing, on the other hand, is itself an analysis of the building. In measured drawings documenters convey the physical relationship of building components and their construction, but also "inscribe" what is unique to the historic asset. The two-dimensional graphical representations, therefore, condense the qualities of the architectural heritage in a manner easily "accessible" and understandable ones who are not experts, whom read the patterns and values embedded in the drawings with respect to the documenters' inquiry.

One outcome of this essay is the identification of the locus of documenters' process of recording and analyzing. Geertz interpreted thick description as an empirical registering of ways of life, researchers looking into cultures as texts, whose texts are spoken, gestured, or written. Documenters' disciplinary formulations of historic architecture, 
thus, do not differ from the anthropological way of recording the cultural context. Documenters' efforts deployed in the documentation scheme means that it is not just the product - measured drawings - that is of significant, but also the process of rendering facts and conclusions. What is revelatory about architectural documentation is not only the production and content of the measured drawings, but the methodology employed in documenters search for the best representation of the essence of historic structures, which involves different levels of interpretation in the form of plan, section, elevation, and interpretive drawings.

Future study and research, therefore, include discussions on the production and utilization of three-dimensional virtual models in view of thick description. Documenters increasingly rely on three-dimensional surrogates to define, treat, and interpret the past usage of structures, yet they still heavily transform the three-dimensional data to twodimensional measured drawings to communicate and disseminate information about the architecture's details, form, fabric, shape, aesthetics, and history. How element of analysis and interpretation is introduced through three-dimensional digital data, consequently, remains a means of significant discussion in the mid of a documentation culture being transformed with advanced surveying practices.

Documenting the architectural environment is often understood as a relatively unproblematic process of surveying and analyzing the historic structure, however, the documentation work is a deeply reflexive process in which analysis and interpretation is inseparable from. Either describing a social issue in the scale of an archaeological landscape or a specific structural detail identified in a historic home, documenters answer inquiries in the form of measured drawings. The educated touch of measured drawings reveals all the historical elements, as well as the research behind the structure, through documenters' careful analysis, observation, and interpretation. With this type of product, documenters amass everything to get a more comprehensive set of final information and focus on the essence of the historic asset. Doing so, architectural documentation becomes an enterprise to take us to the "heart" of the lives of the people of the past.

\section{ACKNOWLEDGEMENTS}

I would like to thank Robert B. Warden, RA, Head of Department of Architecture, College of Architecture, Texas A\&M University, David G. Woodcock FAIA, FSA, FAPT, Professor Emeritus of Architecture, Director Emeritus of Center for Heritage Conservation ( $\mathrm{CHC}$ ), College of Architecture, Texas A\&M University, and Elizabeth I. Louden, PhD, Director of Historic Preservation Programs, College of Architecture, Texas Tech University for our discussions on the modus operandi of architectural documentation projects and the value of drawing. I am also grateful to Günder Varinlioğlu, PhD, Professor, Mimar Sinan Fine Arts University, Director of Boğsak Archaeological Survey (BOGA), for providing me the infrastructure to explore recording and documentation in the scale of a Byzantine settlement.

All the measured drawings shown in the article are retrieved from the Prints and Photographs online catalogue of Library of Congress, Historic American Buildings Survey (HABS) / Historic American Engineering Record
(HAER) / Historic American Landscapes Survey (HALS) collection. Since the inception the program in 1933, HABS later accompanied with HAER (1969) and HALS (2000), have been documenting historic architecture in the U.S. through measured drawings, large-format photographs, and written histories. For further information on the HABS/HAER/HALS collection, see, http://www.loc.gov/pictures/collection/hh/

The measured drawings (except the section drawing of Asa Packer Mansion) discussed in the article were delineated by $\mathrm{CHC}$ documentation teams and then submitted to the HABS/HAER/HALS collection of Library of Congress. Likewise, the three-dimensional scan data is retrieved from the $\mathrm{CHC}$ documentation campaign of the Saint Andrews Episcopal Church, Bryan, Texas, U.S. in 2008. CHC is a professional center for interdisciplinary research and service projects on all aspects of built and natural heritage from cultural heritage recording and documentation to innovative solutions to building preservation. $\mathrm{CHC}$, particularly, supports research of planned and built environments with particular emphasis on their continued use and care. For further information on the $\mathrm{CHC}$, see, http://chc.arch.tamu.edu

The field photograph is retrieved from the 2013 season of work of BOGA. The documentation efforts of BOGA concentrate on the analysis and interpretation of a Byzantine settlement (ca. 200-1000 C.E.) in Mersin, Turkey, where the team has utilized diverse surveying technologies to analyze the architectural varieties in the scale of an ancient rural settlement. For further information on BOGA, see, http:// bogsakarchaeology.org

\section{REFERENCES}

11 April 1914. St. Andrew's New Church. Bryan Daily Eagle and Pilot. Bryan, Texas, U.S.

Akboy S. 2011. The HABS Culture of Documentation with an Analysis of Drawing and Technology. College Station: Texas A\&M University.

Akboy S and Thys-Şenocak L. 2009. "Kültürel Mirasımızın Dijital Belgelenmesi / The Digital Documentation of Our Cultural Heritage." Yapı Architecture, Design, Culture, and Art Magazine 334: 112-116.

Akboy-ilk S. 2013. "The Mediated Environment of Heritage Recording and Documentation." Preservation Education \& Research 6: 7-23.

Akboy-ilk S. 2016. "The Nature of Drawing in the Changing Culture of Architectural Documentation." Journal of Architectural and Planning Research 33: 29-44.

Barthel-Bouchier DL. 1996. Historic Preservation : Collective Memory and Historical Identity. New Brunswick, N.J.: Rutgers University Press.

Belardi P. 2014. Why Architects still Draw : Two Lectures on Architectural Drawing. Cambridge, Massachusetts: The MIT Press.

Bopp SM. 2014. The Historic American Buildings Survey and Interpretive Drawing: Using Digital Tools to Facilitate Comprehensive Heritage Documentation.

Bray Z. 2015. "Anthropology with a Paintbrush: Naturalist-Realist Painting as "Thick Description"." Visual Anthropology Review 31: 119133. https://doi.org/10.1111/var.12076 
Bryan P. 2010. "Metric Survey for Preservation Uses: Past, Present, and Future." APT Bulletin 4/4: 25-29.

Burns JA. 2004a. "Measured Drawings." In: Burns JA (ed) Recording Historic Structures. Wiley.

Burns JA. 2004b. "Overview." In: Burns JA (ed) Recording Historic Structures. Wiley.

https://doi.org/10.1525/california/9780520240247.003.0002

Causey A. 2012. "Drawing Flies: Artwork in the Field." Critical Arts 26: 162-174. https://doi.org/10.1080/02560046.2012.684437

Cuff D. 1991. Architecture: The Story of Practice, Cambridge, Mass.: MIT Press.

Denzin NK. 2001. Interpretive Interactionism, Thousand Oaks, Calif.: Sage Publications. https://doi.org/10.4135/9781412984591 PMid:11381132 PMCid:PMC34437

Eppich R and Chabbi A. 2007. Recording, Documentation and Information Management for the Conservation of Heritage Places: Illustrated examples, Los Angeles: Getty Conservation Institute. PMid:17505184

Evans-Pritchard EE. 1940. The Nuer, a Description of the Modes of Livelihood and Political Institutions of a Nilotic People, Oxford: At the Clarendon Press.

Fisher P. 2012. Seward Plantation - National Register of Historic Places Registration Form. In: Service NP (ed).

Fowler JM. 2003. "The Federal Preservation Program." In: Stipe RE (ed) A Richer Heritage : Historic Preservation in the Twenty-first Century. Chapel Hill: University of North Carolina Press, 35-80.

Geertz C. 1973. The Interpretation of Cultures: Selected Essays. New York: Basic Books.

Geertz C. 1988. Works and Lives : The Anthropologist as Author. Stanford, Calif.: Stanford University Press.

Geertz C. 2000. Available Light : Anthropological Reflections on Philosophical Topics. Princeton, N.J.: Princeton University Press.

Hamlin T. 1944. Greek Revival Architecture in America: Being an Account of Important Trends in American Architecture and American Life Prior to the War between the States. London, New York etc.: Oxford University Press.

Hendrickson C. 2008. "Visual Field Notes: Drawing Insights in the Yucatan." Visual Anthropology Review 24: 117-132. https://doi. org/10.1111/j.1548-7458.2008.00009.x

Hua Y and Yujie Z. 2014. "Transforming Tradition: Performing Wedding Ritual in Modern China." In: Laing J and Frost W (eds) Rituals and Traditional Events in the Modern World. Abingdon, Oxon; New York, NY: Routledge, 41-67. PMid:25497975

Jacobs J. 1961. The Death and Life of Great American Cities, New York: Random House.

Kole SK. 2010. "Dance, Representation, and Politics of Bodies: 'Thick Description' of Tahitian Dance in Hawai'ian Tourism Industry." Journal of Tourism and Cultural Change 8: 183-205. https://doi.org/10.1080/1476 6825.2010 .515989

Lavoie CC. 2010. "The Role of HABS in the Field of Architectural Documentation." APT Bulletin 4/4: 19-24.
Lavoie CC. 2011. "HABS Documentation in the Digital Age." Change Over Time 1: 184.

LeBlanc F and Eppich R. 2005. "Documenting Our Past for the Future." The GCl Newsletter 20.3.

Lévi-Strauss C. 1963. Structural Anthropology. New York: Basic Books.

Louden El and Hughes K. 2005. "Bridging the Gap: Using the 3-D Laser Scanning in Historic-Building Documentation." APT Bulletin Vol.XXXVI: 37-46.

Lyn F and Dulaney R. 2009. "A Case for Drawing." Enquiry 6: 23-30. https://doi.org/10.17831/enq:arcc.v6i1.4

Malinowski B. 2014. Argonauts of the Western Pacific: an Account of Native Enterprise and Adventure in the Archipelagos of Melanesian New Guinea, London; New York: Routledge.

McAlester V 2015. A Field Guide to American Houses : The Definitive Guide to Identifying and Understanding America's Domestic Architecture. New York: Alfred A. Knopf.

Nakashima Degarrod L. 2010. "When Ethnographies Enter Art Galleries." In: Dudley SH (ed) Museum Materialities: Objects, Engagements, Interpretations. xix, 289 p. ed. London; New York: Routledge, 128-142.

Ortner SB. 1999. "Introduction." In: Ortner SB (ed) The Fate of "Culture" : Geertz and beyond. Berkeley: University of California Press, 1-13.

Özkut D. 2008. "Preserving and Documenting the Cultural Heritage." Enquiry 5: 96-103. https://doi.org/10.17831/enq:arcc.v5i2.19

Pérez Gómez A and Pelletier L. 1997. Architectural Representation and the Perspective Hinge, Cambridge, Mass.: MIT Press. PMid:9494215

Pitts, Carolyn. 1984. National of Historic Places Inventory-Nomination Form, prepared for Asa Packer Mansion, Thorpe, Pennsylvania.

Schmitt TM. 2008. "The UNESCO Concept of Safeguarding Intangible Cultural Heritage: Its Background and Marrakchi Roots." International Journal of Heritage Studies 14: 95-111. https://doi. org/10.1080/13527250701844019

Sewell Jr. WH. 1999. "Geertz, Cultural Systems, and History: From Synchrony to Transformation." In: Ortner SB (ed) The Fate of "Culture": Geertz and beyond. Berkeley: University of California Press, 35-55.

Shennan S. 1997. Quantifying Archaeology, Edinburgh: Edinburgh University Press.

Taussig M. 2010. "What Do Drawings Want?" In: Curtis N (ed) The Pictorial Turn. x, 246 p. ed. London: Routledge, 166-177.

Tompkins SK, Anderson RK, Burns JA, et al. 2004. "Interpretive Drawings." In: Burns JA (ed) Recording Historic Structures. Wiley.

Warden R. 2009. "Towards a new Era of Cultural-Heritage Recording and Documentation." APT Bulletin 40: 5-10.

Warden R and Al Ratrout S. 2005. "Moiré Contours for Documenting Petroglyphs at Montezuma Castle.

Warden R and Woodcock D. 2005. "Historic Documentation: A Model of Project Based Learning for Architectural Education." Landscape and Urban Planning 73: 110-119. https://doi.org/10.1016/j. landurbplan.2004.11.003 
Wheatley D. 2000. "Spatial Technology and Archaeological Theory Revisited." In: Lockyear K, T.J.T. Sly and V. Mihăilescu-Bîrliba (ed) CAA96, Computer Applications and Quantitative Methods in Archaeology. Oxford: Archaeopress, 123-132.

Wickstead H. 2008. "Drawing Archaeology." In: Duff L and Sawdon P (eds) Drawing - the Purpose. Bristol; Chicago: Intellect, xi, 141. PMCid:PMC2610381

Woodcock DG. 2006. "Discovery through Documentation: The Investigation of Historic and Cultural Resources." APT Bulletin: 37-44. 